\title{
Proton Mobility in Sulfonated PolyEtherEtherKetone (SPEEK): Influence of Thermal Crosslinking and Annealing
}

\author{
P. Knauth ${ }^{1 *}$, L. Pasquini ${ }^{1,2}$, B. Maranesi ${ }^{1,2}$, K. Pelzer ${ }^{1}$, R. Polini ${ }^{2}$, M. L. Di Vona ${ }^{2}$ \\ Aix Marseille Université - CNRS, Madirel (UMR 7246), Centre St Jérôme, F-13397 Marseille Cedex 20, France \\ 2 University of Rome Tor Vergata, Dip. Scienze e Tecnologie Chimiche, Via della Ricerca Scientifica 1, I-00133 Roma, Italy
}

Received July 08, 2012; accepted September 20, 2012; published online January 16, 2013

\section{Abstract}

Sulfonated PolyEtherEtherKetone (SPEEK) was thermally treated at 180 and $140{ }^{\circ} \mathrm{C}$ to study the effects of polymer cross-linking and annealing on the water uptake and proton conductivity. The kinetics of the cross-linking reaction can be quantitatively described with an activation energy of $(100 \pm 2) \mathrm{kJ} \mathrm{mol}^{-1}$. The proton mobility $\mathrm{u}\left(\mathrm{H}^{+}\right)$depends on the proton concentration $\mathrm{c}\left(\mathrm{H}^{+}\right)$in excellent agreement with the power law $\mathrm{u}\left(\mathrm{H}^{+}\right) \propto \mathrm{c}\left(\mathrm{H}^{+}\right)^{-3}$ observed above the percolation threshold of hydrated nanometric channels. The proton mobility can be described by porosity and tortuosity as phenomenological parameters. Polymer annealing reduces the free volume and porosity of membranes. The proton conductivity can be modulated by changing the hydration number.

Keywords: Ionomer, Kinetics, Membrane, Proton Conductivity

\section{Introduction}

Sulfonated PolyEtherEtherKetone (SPEEK) is considered one of the most promising proton-conducting polymer electrolytes [1-4]. This sulfonated aromatic polymer (SAP) shows the typical attributes of hydrated acidic polymers: hydrophobic polymer domains containing very stable aromatic macromolecular backbones are combined with hydrophilic regions, containing dissociated sulfonic acid groups and water [5, 6]. These nanodomains percolate above a critical concentration of water (or below a certain proton concentration in the acidic solutions present in the hydrophilic domains) [7-9]. The resulting nanocomposite combines very attractive properties for use in demanding environments, such as on the one hand high chemical and thermal stability and good mechanical properties, due to relatively strong and rigid bonds in and between the aromatic rings, and on the other hand high proton conductivity, due to the dissociated and hydrated protons migrating in the acidic solution [10-14]. This microstructure allows responding to a general dilemma found in all solid electrolytes, i.e., that a high ionic conductivity is related to a low thermodynamic and mechanical stability. In other words, solids allowing ionic motion do not show high stability. Here, the separation into hydrophobic and hydrophilic domains allows a good compromise between these conflicting properties.

However, these polymer electrolytes present still much potential for innovation and improvement, as some properties remain still unsatisfactory. For example, it is well-known that the water solubility of the polymer increases with the content of sulfonic acid groups (expressed, e.g., as degree of sulfonation (DS) or ionic exchange capacity IEC in $\mathrm{mmol} \mathrm{g}^{-1}$ ) [15-17]. For a large acidic content, the polymer membranes lose their mechanical strength and swell in water; at even higher sulfonic acid group density, the polymers become water-soluble [18-20]. Nevertheless, the presence of water is essential for a good ionic conductivity of the membranes: water allows the full dissociation of sulfonic acid groups, according to the equilibrium:

$-\mathrm{SO}_{3} \mathrm{H}+\mathrm{H}_{2} \mathrm{O} \rightleftharpoons-\mathrm{SO}_{3}^{-}+\mathrm{H}_{3} \mathrm{O}^{+}$

The proton mobility defined as:

$\mathrm{u}\left(\mathrm{H}^{+}\right)=\frac{\sigma}{F_{\mathrm{c}}\left(\mathrm{H}^{+}\right)}$

- Paper presented at the E-MRS Spring Meeting 2012, Strasbourg, 
is inversely proportional to the proton concentration $\mathrm{c}\left(\mathrm{H}^{+}\right)(F$ is Faraday's constant). Above the percolation threshold of water-containing nanochannels, the relation between proton mobility and proton concentration can be described by a power law [21]:

$\mathrm{u}\left(\mathrm{H}^{+}\right)=A \mathrm{c}\left(\mathrm{H}^{+}\right)^{-3}$

as shown recently for a variety of hydrated acidic polymers, including Nafion and various SAP. The presence of a large quantity of water is thus beneficial for the proton conductivity, but not for the mechanical properties.

There are several strategies that might be followed to further improve the properties of SAP and find an optimal balance between mechanical stability on the one hand and proton conductivity on the other, including (i) the introduction of a secondary phase for the realization of composite polymers [22-25], (ii) the formation of covalent cross-linking bonds between macromolecular chains, realized by innovative chemical synthesis $[26,27]$ or by solvothermal treatments $[28,29]$.

According to usual $X$-ray diffraction, SPEEK appears as a fully amorphous polymer, although the presence of a small quantity of crystalline phase has been conjectured [30, 31]. The introduction of sulfonic groups in main chains of PEEK introduces asymmetries and hence suppresses local chain order, which is the reason of the polymer crystallinity. Given the out-of-equilibrium nature of the polymer, the membrane history is thus of fundamental importance for the observed properties and thermal treatments in presence or absence of solvents can change them significantly. The formation of sulfone bridges, cross-linking (XL) SPEEK chains, by a thermal treatment above $150{ }^{\circ} \mathrm{C}$ in presence of small quantities of residual casting solvent DMSO has been demonstrated by various spectroscopic techniques [29, 32]. The formation of covalent cross-links occurs by electrophilic aromatic substitution with formation of $\mathrm{SO}_{2}{ }^{+}$electrophiles according to Scheme 1 .

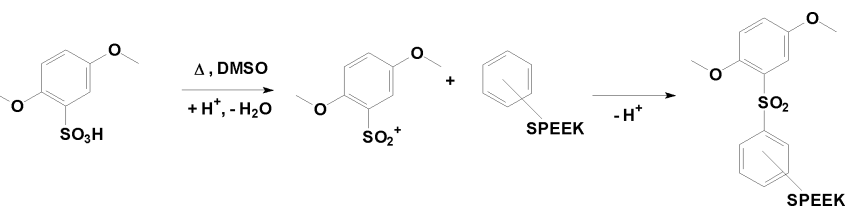

Scheme 1 Simplified mechanism for the formation of cross-linked SPEEK.

The reticulation is followed by important changes of mechanical properties and a reduced solubility in various solvents $[18,33]$. This strategy has been followed in previous investigations to improve the stiffness and mechanical strength of the polymer, but the influence on the proton conductivity was only marginally studied.

Another important strategy for the improvement of polymers is annealing [34-37]: in that case the polymer is treated at a distinctly lower temperature, below the one needed for building covalent bonds between macromolecules and creating cross-links, but sufficiently high to induce irreversible changes of conformations or remove entanglements of macromolecular chains. In general, annealing leads to a reduction of free volume in the polymer [38]. In order to observe an unam- biguous effect, the temperature chosen for the annealing treatment was $140{ }^{\circ} \mathrm{C}$, where only little reticulation is expected.

In this work, we thus investigate the influence of heat treatments at high $\left(180{ }^{\circ} \mathrm{C}\right)$ and intermediate temperature $\left(140{ }^{\circ} \mathrm{C}\right)$ on the water uptake (WU) and proton conduction properties of SPEEK membranes.

\section{Experimental}

\subsection{Synthesis of SPEEK}

PolyEtherEtherKetone (PEEK, Victrex 450P, MW = 38 300, 132 repeat units per mole) was dissolved in concentrated sulfuric acid (Fluka 95-98\%), with the help of a mechanic stirrer, in the ratio 1:35 $\mathrm{g} \mathrm{mL}^{-1}$ at room temperature under $\mathrm{N}_{2}$. After dissolution (about $3 \mathrm{~h}$ ) the solution was heated at $50{ }^{\circ} \mathrm{C}$ for $2-$ 4 days in order to obtain a large DS (in the range $0.8-1$ ). A white precipitate was obtained adding the solution, under continuous stirring, into an excess of ice-cold water. After resting overnight, the precipitate was filtered and washed with water several times using a dialysis membrane (SigmaAldrich D9402) to neutral $\mathrm{pH}$ in order to eliminate completely the residual sulfuric acid. The sulfonated polymer (SPEEK) was then dried overnight at $80^{\circ} \mathrm{C}$.

\subsection{Membrane Preparation}

Membranes were prepared using DMSO (Fluka, >99\%) as casting solvent. In a typical experiment SPEEK was dissolved in DMSO in a $10: 1 \mathrm{~g} \mathrm{~L}^{-1}$ ratio at $80-90{ }^{\circ} \mathrm{C}$. The resulting solution was evaporated under continuous stirring to about half of the original volume to obtain a viscous liquid. The solution was then coated on a glass plate and heated at $120{ }^{\circ} \mathrm{C}$ for $24 \mathrm{~h}$. After cooling to room temperature, the resulting membranes were peeled off; all membranes were thus submitted to this first thermal treatment. The membrane thickness was in the range $60-80 \mu \mathrm{m}$. Most membranes treated at $120^{\circ} \mathrm{C}$ were submitted to a second thermal treatment, performed at $180{ }^{\circ} \mathrm{C}$ for various times between 3 and $24 \mathrm{~h}$. Some samples treated for 3,6 , or $8 \mathrm{~h}$ at $180{ }^{\circ} \mathrm{C}$ were submitted to a third annealing treatment at $140{ }^{\circ} \mathrm{C}$ for different times $(1,3,5$, or 7 days). Samples without thermal treatment at $180{ }^{\circ} \mathrm{C}$ will be called "untreated."

\subsection{Characterization of SPEEK Membranes}

The DS of SPEEK was evaluated both by titration and by ${ }^{1} \mathrm{H}$ NMR spectroscopy [39]. The ion-exchange capacity of membranes (IEC, in milliequivalents of sulfonic acid groups per gram of dry polymer) was determined by titration. To eliminate the residual casting solvent before titration, which can affect IEC, membranes were treated with $5 \mathrm{M} \mathrm{H}_{2} \mathrm{SO}_{4}$ at room temperature for $2 \mathrm{~h}$ and then washed until neutral $\mathrm{pH}$. The membranes were dried over $\mathrm{P}_{2} \mathrm{O}_{5}$ for one night and then weighed. The titration was performed by immersing the dry membranes in a $1.5 \mathrm{~N} \mathrm{NaCl}$ solution under stirring at room 
temperature for one night to exchange the $\mathrm{H}^{+}$ions with $\mathrm{Na}^{+}$ ions [40]. The $\mathrm{pH}$ was recorded potentiometrically during titration of exchanged $\mathrm{H}^{+}$ions with a $0.02 \mathrm{~N} \mathrm{NaOH}$ solution. In the following $\operatorname{IEC}^{\circ}$ (and $\mathrm{DS}^{\circ}$ ) is the ion exchange capacity of untreated membranes and IEC (DS) represents the ion exchange capacity after the thermal treatments. The relation between IEC and DS was already reported. [32]

The DS of membranes was also determined by high resolution thermogravimetric analysis (TGA Q500, TA Instruments) [33].

The WU was determined by immersion in water at various temperatures, including 25 and $100{ }^{\circ} \mathrm{C}$. The membranes were weighed in the wet state; the dry mass was determined after drying for $48 \mathrm{~h}$ over $\mathrm{P}_{2} \mathrm{O}_{5}$. The $\mathrm{WU}$ is calculated according to the equation:

$\mathrm{WU}=\frac{m(\text { wet })-m(\text { dry })}{m(\text { dry })}$

\subsection{Conductivity Measurements}

The impedance measurements were performed in fully humidified conditions according to two different techniques: (i) measurements in three-electrode configuration in aqueous solution, (ii) measurements in a Swagelok cell. The a.c. voltage amplitude was $10 \mathrm{mV}$ and the frequency range from 0.1 to $10^{5} \mathrm{~Hz}$.

The three-electrode cell comprised the working electrode made from stainless steel (304 L) with surface area $0.19 \mathrm{~cm}^{2}$, on which the membrane was fixed, a saturated calomel electrode as reference electrode and a platinum grid as counter electrode at $0.7 \mathrm{~cm}$ distance from the working electrode. The measurements were made at $25{ }^{\circ} \mathrm{C}$ in $5 \mathrm{M} \mathrm{H}_{2} \mathrm{SO}_{4}$ solution, whose conductivity is known [41].

In the Swagelok cell, the membrane was sandwiched between a stainless steel counter electrode and a stainless steel working electrode of $0.19 \mathrm{~cm}^{2}$ area. A drop of water was added to keep fully humidified conditions and the cell was closed with controlled force, in order to ensure a reproducible contact between the membrane and the electrodes, and kept at constant temperature at $25^{\circ} \mathrm{C}$.

The consistency of results obtained by the two different techniques was verified carefully during this work.

\section{Results and Discussion}

\subsection{Thermal Treatment at $180^{\circ} \mathrm{C}$}

The variation of the IEC of SPEEK as function of the time of the thermal treatment is shown in a semi-logarithmic representation in Figure 1. The figure includes two families of samples, one with initial IEC $=2.7 \mathrm{meq}^{-1}(\mathrm{DS}=1)$ and one with IEC $=2.5 \mathrm{meq} \mathrm{g}^{-1} \quad(\mathrm{DS}=0.9)$. The cross-linking reaction is considered to be an electrophilic aromatic substitution $\left(\mathrm{S}_{\mathrm{E}} \mathrm{Ar}\right)$ with a Friedel-Crafts type acylation mechanism [28]. We have previously outlined a chemical kinetics model based on sequential reactions:

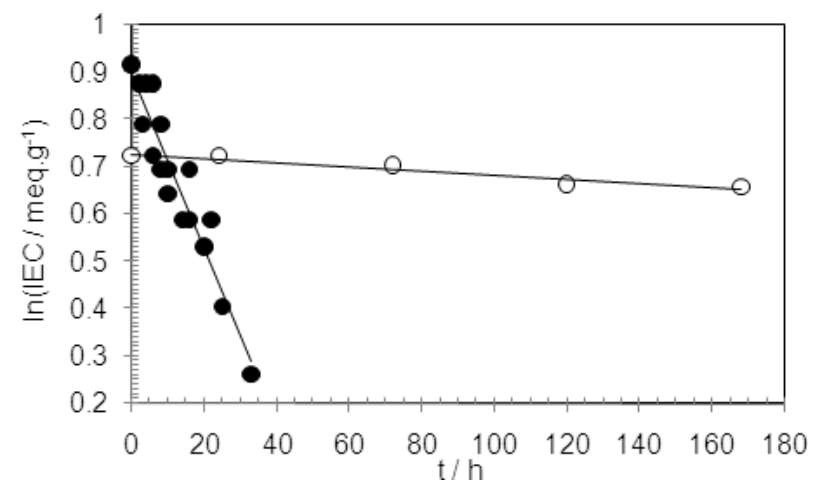

Fig. 1 Dependence of the ionic exchange capacity (IEC) of SPEEK membranes on the time of thermal treatments at $180^{\circ} \mathrm{C}(0)$ or $140{ }^{\circ} \mathrm{C}(\mathrm{O}$, after $6 \mathrm{~h}$ at $180^{\circ} \mathrm{C}$ ). The IEC after $6 \mathrm{~h}$ at $180^{\circ} \mathrm{C}$ is therefore identical to the value "after $0 \mathrm{~h}$ " at $140^{\circ} \mathrm{C}$. The lines are exponential fits according to Eq. (12). The figure includes two families of samples, one with initial $\mathrm{IEC}^{\circ}=2.7 \mathrm{meq} \mathrm{g}^{-1} \quad(\mathrm{DS}=1)$ and one with $\mathrm{IEC}^{\circ}=2.5 \mathrm{meq} \mathrm{g}^{-1}$ (DS $=0.9$ ).

$\mathrm{S} \stackrel{k_{1}}{\longrightarrow} \mathrm{E}+\mathrm{S} \stackrel{k_{2}}{\longrightarrow} \mathrm{C}$

In this sequence, $\mathrm{S}$ is SPEEK polymer, $\mathrm{E}$ the electrophilic sulfonium intermediate, and C is the cross-linked polymer. The kinetic analysis leads to the following equations:

$$
\begin{aligned}
& -\frac{\mathrm{d}[\mathrm{S}]}{\mathrm{d} t}=k_{1}[\mathrm{~S}]+k_{2}[\mathrm{~S}][\mathrm{E}] \\
& \frac{\mathrm{d}[\mathrm{E}]}{\mathrm{d} t}=k_{1}[\mathrm{~S}]-k_{2}[\mathrm{~S}][\mathrm{E}] \\
& \frac{\mathrm{d}[\mathrm{C}]}{\mathrm{d} t}=k_{2}[\mathrm{~S}][\mathrm{E}]=-\frac{1}{2}\left(\frac{\mathrm{d}[\mathrm{S}]}{\mathrm{d} t}+\frac{\mathrm{d}[\mathrm{E}]}{\mathrm{d} t}\right)
\end{aligned}
$$

In these equations, the terms in brackets represent the concentrations and $k_{1}$ and $k_{2}$ are the rate constants of the first and second sequential reactions. The third kinetic equation is not independent of the first two, but is related by the stoichiometry of the overall reaction.

Three different rate-determining steps can be recognized in electrophilic aromatic substitution reactions: (i) the formation of the electrophile, (ii) the formation of the Wheland intermediate, (iii) the proton-removal to the final product (aromatization step) [42]. Assuming that the formation of the electrophile is the rate-determining step $\left(k_{1} \ll k_{2}\right)$, one can apply the stationary-state approximation:

$\frac{\mathrm{d}[\mathrm{E}]}{\mathrm{d} t} \approx 0=k_{1}[\mathrm{~S}]-k_{2}[\mathrm{~S}][\mathrm{E}]$

One obtains then:

$[\mathrm{E}]=\frac{k_{1}}{k_{2}}$

and

$\frac{\mathrm{d}[\mathrm{C}]}{\mathrm{d} t}=k_{2}[\mathrm{~S}][\mathrm{E}]=k_{1}[\mathrm{~S}]$

and finally:

$\frac{\mathrm{d}[\mathrm{S}]}{\mathrm{d} t}=-2 k_{1}[\mathrm{~S}]$ 
The cross-linking reaction can thus be considered a first order reaction. The temperature dependence of the rate constant $k$ is described by the Arrhenius equation:

$k=A \mathrm{e}^{-E_{A} / R T}$

where $R$ is the ideal gas constant; $A$ the pre-exponential factor, $T$ the absolute temperature, and $E_{A}$ the activation energy of the reaction. The rate constant $k_{1}$ can be expressed using the Arrhenius equation:

$-\frac{\mathrm{d}[\mathrm{S}]}{\mathrm{d} t}=2[\mathrm{~S}] A \mathrm{e}^{-E_{A} / R T}$

where [S] is the concentration of SPEEK, i.e., of sulfonic acid groups, which decreases during the $\mathrm{XL}$ reaction. An exponential decrease of the sulfonic acid group concentration [S] should indeed be observed with time $t$.

This concentration can be expressed by the ionic exchange capacity IEC. This leads after an elementary integration step to the equation:

$\ln \left(\frac{\mathrm{IEC}^{\circ}}{\mathrm{IEC}}\right)=2 A \mathrm{e}^{-E_{A} / R T} t$

$\mathrm{IEC}^{\circ}$ is the ionic exchange capacity of the untreated membrane, IEC that after an isothermal thermal treatment time $t$. The dependence of the IEC on time at $180{ }^{\circ} \mathrm{C}$ is indeed in good approximation exponential with a rate constant: $k=0.0193 \mathrm{~h}^{-1}=5.4 \times 10^{-6} \mathrm{~s}^{-1}$.

The Eq. (12) allows predicting and calculating the expected effect of a thermal treatment and its "thermal budget" depending on temperature $T$ and time $t$.

The WU determined after full immersion in water at 25 or $100{ }^{\circ} \mathrm{C}$ for $24 \mathrm{~h}$ (Figure 2a and b) can be combined with the IEC data to calculate the molar proton concentration $\mathrm{c}\left(\mathrm{H}^{+}\right)$(in mol L ${ }^{-1}$ ) in the hydrated acidic solution according to:

$\mathrm{c}\left(\mathrm{H}^{+}\right)=\frac{\mathrm{IEC} \cdot d}{\mathrm{WU}}$

where $d$ is the density of the aqueous solution, taken as 1 . The relations of the hydration number $\lambda$ and the volume fraction of hydrophilic domains $\phi$ with the proton concentration are:

$\lambda=\frac{1000 \cdot d}{\mathrm{M}\left(\mathrm{H}_{2} \mathrm{O}\right) \cdot \mathrm{c}\left(\mathrm{H}^{+}\right)}$

$\phi=\frac{\operatorname{IEC} \rho}{\operatorname{IEC} \rho+\mathrm{c}\left(\mathrm{H}^{+}\right)}$

The proton conductivity data determined by the two independent techniques (Figure 3) can be transformed into an effective proton mobility (in $\mathrm{cm}^{2} \mathrm{~V}^{-1} \mathrm{~s}^{-1}$ ) in the aqueous acidic solution contained in the polymer matrix according to Eq. (2). $\mathrm{u}\left(\mathrm{H}^{+}\right)$can be plotted as function of the square root of proton concentration like in the classical Kohlrausch law (Figure 4). The concentration dependence is much stronger, described by Eq. (3), due to the electrostatic interactions between the negatively charged sulfonate ions fixed on the polymer chains and the protons moving in the acidic solution. The spatial separation between sulfonate anions and
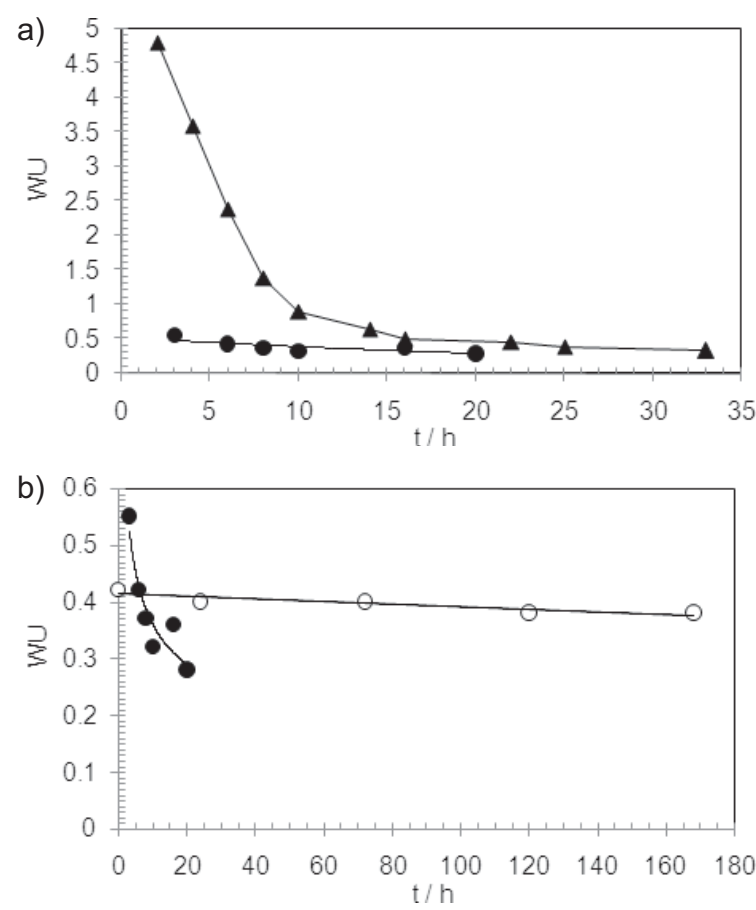

Fig. 2 (a) Dependence of the WU (WU) of SPEEK membranes in liquid water at $25^{\circ} \mathrm{C}(\mathbf{O})$ and $100{ }^{\circ} \mathrm{C}(\mathbf{A})$ on the time of thermal treatment at $180^{\circ} \mathrm{C}$. (b) Dependence of the WU of SPEEK membranes in liquid water at $25^{\circ} \mathrm{C}$ on the time of thermal treatments at $180^{\circ} \mathrm{C}(0)$ or $140^{\circ} \mathrm{C}(\mathrm{O}$, after $6 \mathrm{~h}$ at $180^{\circ} \mathrm{C}$ ). The $\mathrm{WU}$ after $6 \mathrm{~h}$ at $180^{\circ} \mathrm{C}$ is therefore identical to the value "after $0 \mathrm{~h}$ " at $140^{\circ} \mathrm{C}$.

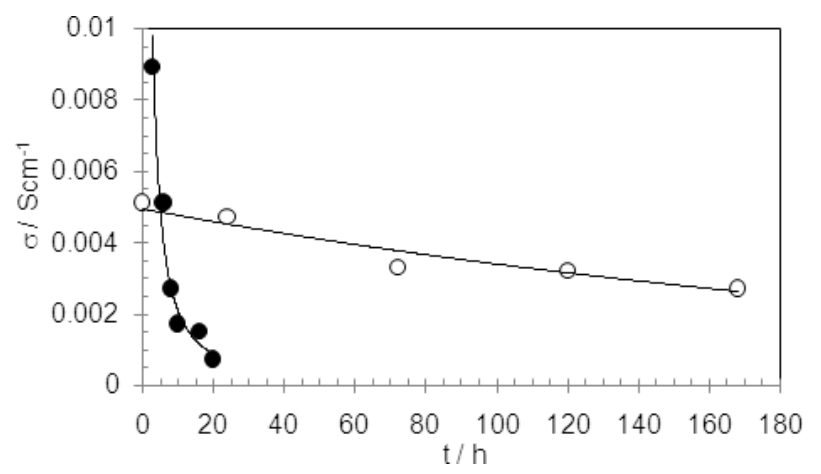

Fig. 3 Dependence of the proton conductivity $\sigma$ of SPEEK membranes on the time of thermal treatments at $180^{\circ} \mathrm{C}(0)$ or $140^{\circ} \mathrm{C}(\mathrm{O}$, after $6 \mathrm{~h}$ at $\left.180^{\circ} \mathrm{C}\right)$. The proton conductivity after $6 \mathrm{~h}$ at $180^{\circ} \mathrm{C}$ is therefore identical to the value "after $0 \mathrm{~h}$ " at $140^{\circ} \mathrm{C}$.

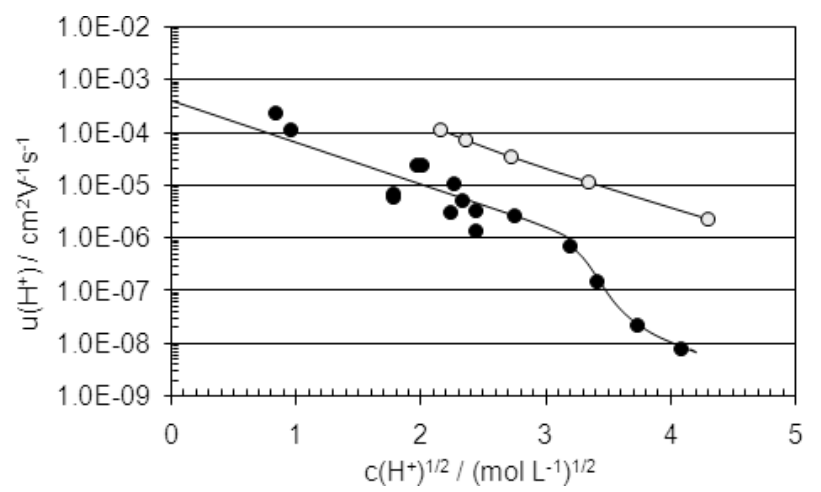

Fig. 4 Semi-logarithmic plot of proton mobility vs. square root of proton concentration in SPEEK (O) and Nafion (O). 
protons leads to electrostatic forces, which cause a non-homogeneous arrangement of protons inside the solution and preferred proton localization near sulfonate groups. The proton mobility inside Nafion membranes, calculated from literature data [5], is also reported.

The sudden change of slope for SPEEK at a proton concentration around $10 \mathrm{~mol} \mathrm{~L}^{-1}$ (corresponding according to Eqs. (9) and (10) to $\lambda \approx 5$ and $\phi \approx 0.25$ ) can be related to the percolation threshold of hydrated channels through the polymer matrix. For randomly dispersed spherical hydrated clusters in a $3 \mathrm{D}$ polymer matrix, the percolation threshold for conduction, $\phi_{c}$, should indeed be observed at a volume fraction near 0.3 [43]. In other words, sulfonic acid groups aggregate in spherical domains in SPEEK and must absorb sufficient water to achieve a hydrophilic volume fraction $\phi_{c} \approx 0.25$ or $\lambda \approx 5$ for conduction paths to cross the polymer electrolyte [43]. The lamellar structure suggested for Nafion has instead plate-like hydrophilic domains. The plates percolate through the hydrophobic matrix at a much lower volume fraction [44]. Analytical calculations [45] and numerical simulations [46] performed in recent years have consistently predicted a percolation threshold at $\lambda \approx 5$ for SPEEK, whereas no such threshold was found for Nafion, apparently due to the better nanophase separation in the latter. The experiments on SPEEK are in good agreement with this prediction.

The very low proton mobility determined below the percolation threshold corresponds to proton hopping between sulfonic acid groups in the dry state. One notices the good parallelism of curves for Nafion and SPEEK above the percolation threshold $\phi_{c}$ : the conductivity should increase according to a power law in this domain:

$\sigma \approx\left(\phi-\phi_{c}\right)^{\alpha}$

The exponent $a$ is a universal constant, depending on the dimensionality of the network: $a \approx 2$ for a 3D network [47]. Introducing $\phi_{p}$ the volume fraction of solid polymer $\left(\phi_{p}=1-\phi\right)$, we can write:

$\phi=\frac{\mathrm{IEC} \cdot \rho \cdot \phi_{P}}{\mathrm{c}\left(\mathrm{H}^{+}\right)}$

Combining Eq. (2), (16), and (17) one can nicely interpret the power law (Eq.3) observed above the percolation threshold.

From a practical point of view, the effective proton mobility is strongly dependent on the water content of the samples, i.e., it can be changed by changing the WU conditions. For example, a membrane immersed in water at $100{ }^{\circ} \mathrm{C}$ has a higher hydration number and a larger proton mobility than a sample equilibrated in liquid water at $25{ }^{\circ} \mathrm{C}$. The "memory" of the membrane [48] was verified experimentally: a SPEEK membrane equilibrated at high temperature in water keeps the same hydration number even when the membrane is later equilibrated in water at lower temperature. This is an important way to optimize the proton mobility. Although reproducible steady-state properties can be measured for SPEEK membranes, they remain amorphous, out-of-equilibrium materials, which are sensitive to the materials history.
The effective proton mobility $\mathrm{u}\left(\mathrm{H}^{+}\right)$above the percolation threshold in hydrated acidic polymers can be related, as shown for the proton conductivity in ref. [45], to the membrane porosity $\varepsilon$ and tortuosity $\tau$ :

$\mathrm{u}\left(\mathrm{H}^{+}\right)=\frac{\varepsilon}{\tau} \mathrm{u}\left(\mathrm{H}^{+}\right)^{\circ}$

$\mathrm{u}\left(\mathrm{H}^{+}\right)^{\circ}$ is the proton mobility in an aqueous acidic solution not contained in a polymer matrix. Porosity and tortuosity are phenomenological parameters used to describe the microstructure of the polymeric material. The porosity corresponds in our case to the volume occupied by the acidic solution $V_{\text {sol }}$ divided by the total volume of the polymer electrolyte $V_{\text {total }}$ ( $\left.\varepsilon=V_{\text {sol }} / V_{\text {total }}\right)$. By definition $\varepsilon<1$; the case $\varepsilon=1$ corresponds evidently to an acidic solution not contained in a polymer matrix. Tortuosity is defined as the distance that a proton has to move to cross the membrane divided by the membrane thickness. By definition, tortuosity $\tau>1 ; \tau=1$ corresponds to the case of channels, which are ideally straight and perpendicular to the polymer/electrode interface. Porosity and tortuosity allow a mean-field description of the proton-conducting membrane: it is evident that the effective proton mobility increases with the porosity and decreases with the tortuosity. Swelling of the membrane in water corresponds to an increase of $\varepsilon$; the formation of covalent crosslinking bonds is expected to reduce the tortuosity $\tau$. Both processes should therefore change the proton mobility in hydrated acidic polymers.

The extrapolated proton mobility at infinite dilution for SPEEK, around $3 \times 10^{-4} \mathrm{~cm}^{2} \mathrm{~V}^{-1} \mathrm{~s}^{-1}$ (Figure 3), is about one order of magnitude below the value in aqueous solutions not contained in a polymer matrix $\left(3.6 \times 10^{-3} \mathrm{~cm}^{2} \mathrm{~V}^{-1} \mathrm{~s}^{-1}\right.$ at $25{ }^{\circ} \mathrm{C}$ [49]). From this difference, a ratio $\varepsilon / \tau \approx 0.1$ can be estimated for SPEEK, which is largely below that for Nafion, in accordance with the larger hydrophobic/hydrophilic domain separation, leading especially to lower tortuosity. The surprisingly high proton conductivity of thermally cross-linked ionomers at high humidification can be related to a reduction of tortuosity due to straightening of cross-linked macromolecular chains and an increase of porosity due to the high hydration level.

\subsection{Annealing at $140^{\circ} \mathrm{C}$}

Although the temperature of annealing is relatively low, a slight decrease of IEC can still be observed for annealing times above 3 days. The annealing time dependence of IEC (Figure 1) can be well described by Eq. (12) with a rate constant $k=4.6 \times 10^{-4} \mathrm{~h}^{-1}=1.3 \times 10^{-7} \mathrm{~s}^{-1}$. The rate constants at the two temperatures can be combined to estimate the activation energy for macromolecular cross-linking by formation of sulfone bridges, according to the Arrhenius law (Eq. 10). A quantitative agreement with experimental data is obtained in Eq. (12) with $A=(5 \pm 1) 10^{5} \mathrm{~s}^{-1}$ and $E_{A}=(100 \pm 2) \mathrm{kJ} \mathrm{mol}^{-1}$ (Figure 5). We have in a previous study [28] used the activation energy for the sulfonation of PEEK $\left(60 \mathrm{~kJ} \mathrm{~mol}^{-1}\right)$ as lower bound value for the activation energy of the cross-linking 


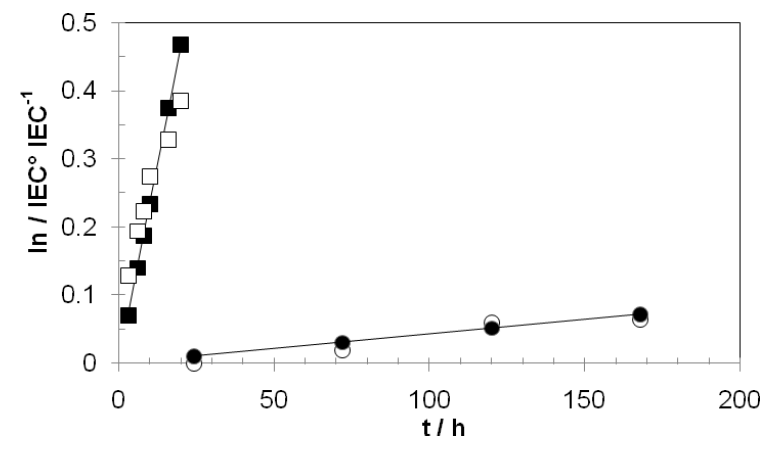

Fig. 5 Comparison of experimental values (open symbols) and calculated values according to Eq. (12) (full symbols) of the ratio $\ln (\mathrm{IEC} / \mathrm{IEC}$ ) for thermal treatments at $180^{\circ} \mathrm{C}$ (squares) and $140^{\circ} \mathrm{C}$ (circles).

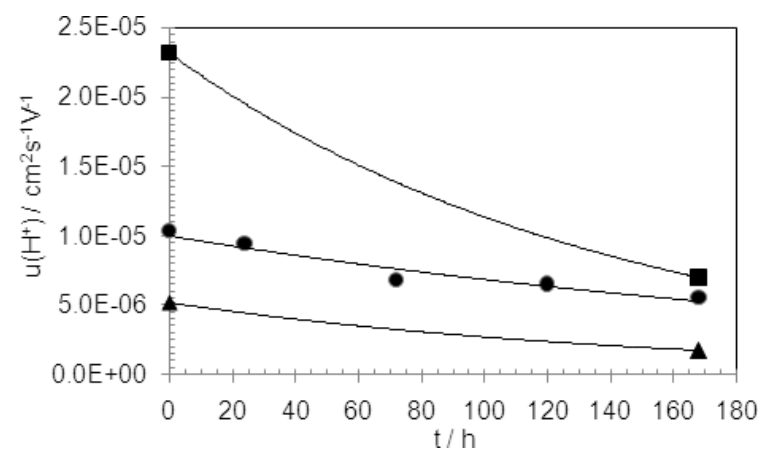

Fig. 6 Dependence of the proton mobility in SPEEK membranes on the time of annealing at $140^{\circ} \mathrm{C}$. Time of heat treatment at $180^{\circ} \mathrm{C}:-3 \mathrm{~h}$, $6 \mathrm{~h}, \Delta 8 \mathrm{~h}$.

reaction. As the sulfonation of PEEK is possible in solvent at $50{ }^{\circ} \mathrm{C}$ and the $\mathrm{XL}$ reaction of SPEEK is observed only at much higher temperature, this value seems consistent with these experimental observations. A prefactor of the order of $10^{5} \mathrm{~s}^{-1}$ is typical for solid-state reactions [50]. Using the "thermal budget" Eq. (12), we can calculate that $1 \mathrm{~h}$ treatment at $180{ }^{\circ} \mathrm{C}$ has a similar effect as $110 \mathrm{~h}$ at $140{ }^{\circ} \mathrm{C}$.

The WU (Figure 2b) and proton conductivity (Figure 4) both decrease with annealing time. Interesting is the calculation of the effective proton mobility for several initial degrees of cross-linking, which decreases exponentially with annealing time, although the proton concentration does not change significantly (Figure 5). According to the Eq. (18), the interpretation for this result is that the ratio $\varepsilon / \tau$ of the membrane changes with annealing time. The influence on the membrane tortuosity can be different in dependence of the type of polymer chains (flexible or rigid); the most plausible explanation is a reduction of membrane porosity. The annealing step eliminates defects and ameliorates the packing of polymer chains so that a densification and a reduction of free volume are observed. A reduction of membrane free volume by annealing has been conjectured several times [51]. Our results are an experimental verification of this prediction.

The reduction of channel size by cross-linking due to the low bond length of sulfone bridges $(0.26 \mathrm{~nm})$ has been already mentioned previously [32]. One can assume that the annealing treatment is effective for aligning macromolecular chains and reducing channel size homogeneously. From a practical point of view, it is however clear that the experimental conditions of annealing and cross-linking the polymer must be optimized in order to get the highest possible proton conductivity.

\section{Conclusions}

For the improvement of polymer electrolytes having high proton conductivity at low relative humidity, the shape, and tortuosity of hydrophilic domains formed in the polymer matrix is an important point to consider. The proton mobility data of SPEEK obtained over the largest proton concentration range ever investigated confirm theoretical predictions. The effective proton mobility depends on the porosity and tortuosity of the polymer matrix and the percolation threshold of the nanometric channels containing the acidic solution. It is shown that although some sulfonic acid groups are sacrificed by cross-linking macromolecular chains, this reduction of IEC can be counterbalanced to some degree by increasing the hydration level, given that the proton mobility is strongly enhanced at low proton concentration. Cross-linking SPEEK can thus be a valid strategy to enhance the mechanical properties of the polymer without compromising the proton conductivity. Polymer annealing leads instead to a decrease of proton mobility, probably due to a reduction of the free volume and should be applied carefully.

\section{Acknowledgments}

The financial support by the European Union in the framework of FP7 JU-FCH project "Lolipem" (GA 245339) is gratefully acknowledged.

\section{References}

[1] J. Roziere, D. J. Jones, Annu. Rev. Mater. Res. 2003, 33, 503.

[2] B. Smitha, S. Sridhar, A. A. Khan, J. Membr. Sci. 2005, $259,10$.

[3] H. Y. Hou, M. L. Di Vona, P. Knauth, ChemSusChem 2011, 4, 1526.

[4] L. Li, J. Zhang, Y. X. Wang, J. Membr. Sci. 2003, 226, 159.

[5] K. Kreuer, S. Paddison, E. Spohr, M. Schuster, Chem. Rev. 2004, 104, 4637.

[6] S. J. Paddison, Annu. Rev. Mater. Res. 2003, 33, 289.

[7] C. V. Mahajan, V. Ganesan, J. Phys. Chem. B 2010, 114, 8357.

[8] L. Pisani, J. Power Sources 2009, 194, 451.

[9] P. Knauth, E. Sgreccia, A. Donnadio, M. Casciola, M. L. Di Vona, J. Electrochem. Soc. 2011, 158, B159.

[10] S. Kaliaguine, S. D. Mikhailenko, K. P. Wang, P. Xing, G. Robertson, M. Guiver, Catal. Today 2003, 82, 213. 
[11] N. N. Fathima, R. Aravindhan, D. Lawrence, U. Yugandhar, T. S. R. Moorthy, B. U. Nair, J. Sci. Ind. Res. 2007, 66, 209.

[12] Y. S. Kim, L. Dong, M. A. Hickner, T. E. Glass, V. Webb, J. E. McGrath, Macromolecules 2003, 36, 6281.

[13] C. H. Park, C. H. Lee, M. D. Guiver, Y. M. Lee, Prog. Polym. Sci. 2012, 36, 1443.

[14] N. Li, C. Wang, S. Y. Lee, C. H. Park, Y. M. Lee, M. D. Guiver, Angew. Chem. Int. Ed. 2011, 50, 9158.

[15] R. C. Jiang, H. R. Kunz, J. M. Fenton, J. Power Sources 2005, 150, 120.

[16] Y. Paik, S. A. Chae, O. H. Han, H. S. Youp, H. H. Yong, Polymer 2009, 50, 2664.

[17] E. Fontananova, V. Cucunato, E. Curcio, F. Trotta, M. Biasizzo, E. Drioli, G. Barbieri, Electrochim. Acta 2012, 66, 164 .

[18] E. Sgreccia, J. F. Chailan, M. Khadhraoui, M. L. Di Vona, P. Knauth, J. Power Sources 2010, 195, 7770.

[19] D. X. Luu, D. Kim, J. Power Sources 2011, 196, 10584.

[20] R. Borup, J. Meyers, B. Pivovar, Y. S. Kim, R. Mukundan, N. Garland, D. Myers, M. Wilson, F. Garzon, D. Wood, P. Zelenay, K. More, K. Stroh, T. Zawodzinski, J. Boncella, J. E. McGrath, M. Inaba, K. Miyatake, M. Hori, K. Ota, Z. Ogumi, S. Miyata, A. Nishikata, Z. Siroma, Y. Uchimoto, K. Yasuda, K. I. Kimijima, N. Iwashita, Chem. Rev. 2007, 107, 3904.

[21] P. Knauth, M. L. Di Vona, Solid State Ionics 2012, 225, 255.

[22] M. L. Di Vona, E. Sgreccia, S. Licoccia, M. Khadhraoui, R. Denoyel, P. Knauth, Chem. Mater. 2008, 20, 4327.

[23] M. L. Di Vona, E. Sgreccia, A. Donnadio, M. Casciola, J F. Chailan, G. Auer, P. Knauth, J. Membr. Sci. 2011, $369,536$.

[24] E. Sgreccia, M. L. Di Vona, S. Licoccia, M. Sganappa, M. Casciola, J. F. Chailan, P. Knauth, J. Power Sources 2009, 192, 353.

[25] F. Celso, S. D. Mikhailenko, S. Kaliaguine, U. L. Duarte, R. S. Mauler, A. S. Gomes, J. Membr. Sci. 2009, 336, 118.

[26] M. L. Di Vona, D. Marani, C. D'Ottavi, M. Trombetta, E. Traversa, I. Beurroies, P. Knauth, S. Licoccia, Chem. Mater. 2006, 18, 69.

[27] J. A. Kerres, Fuel Cells 2005, 5, 230.

[28] M. L. Di Vona, E. Sgreccia, S. Licoccia, G. Alberti, L. Tortet, P. Knauth, J. Phys. Chem. B 2009, 113, 7505.

[29] M. L. Di Vona, E. Sgreccia, M. Tamilvanan, M. Khadhraoui, C. Chassigneux, P. Knauth, J. Membr. Sci. 2010, 354,134
[30] A. Reyna-Valencia, S. Kaliaguine, M. Bousmina, J. Appl. Polym. Sci. 2006, 99, 756.

[31] A. Carbone, R. Pedicini, G. Portale, A. Longo, L. D'Ilario, E. Passalacqua, J. Power Sources 2006, 163, 18.

[32] M. L. Di Vona, G. Alberti, E. Sgreccia, M. Casciola, P. Knauth, Int. J. Hydrogen Energy 2012, 37, 8672.

[33] P. Knauth, H. Hou, E. Bloch, E. Sgreccia, M. L. Di Vona, J. Anal. Appl. Pyrolysis 2011, 92, 361.

[34] A. Arzak, J. I. Eguiazabal, J. Nazabal, Polym. Eng. Sci. 1991, 31, 586.

[35] J. E. Hensley, J. D. Way, S. F. Dec, K. D. Abney, J. Membr. Sci. 2007, 298, 190.

[36] A. Danch, W. Osoba, J. Thermal Anal. Calorimetry 2004, $78,923$.

[37] J. E. Lincoln, R. J. Morgan, E. E. Shin, J. Polym. Sci. Part B Polym. Phys. 2001, 39, 2947.

[38] R. J. Young, P. A. Lovell, Introduction to Polymers, 2nd Ed., Chapman \& Hall, New York, USA, 1991.

[39] S. M. J. Zaidi, S. D. Mikhailenko, G. P. Robertson, M. D. Guiver, S. Kaliaguine, J. Membr. Sci. 2000, 173, 17.

[40] G. Alberti, M. Casciola, L. Massinelli, B. Bauer, J. Membr. Sci. 2001, 185, 73.

[41] R. C. Weast, Handbook of Chemistry and Physics, $61^{\text {st }}$ Ed., CRC Press, Boca Raton, 1981.

[42] G. A. Olah, T. Matew, G. K. Surya Prakash, Chem. Commun. 2001, 1696.

[43] X. M. Wu, X. W. Wang, G. H. He, J. Benziger, J. Polym. Sci. Part B Polym. Phys. 2011, 49, 1437.

[44] M. Eikerling, A. A. Kornyshev, U. Stimming, J. Phys. Chem. B 1997, 101, 10807.

[45] L. Pisani, M. Valentini, D. H. Hofmann, L. N. Kuleshova, B. D'Aguanno, Solid State Ionics 2008, 179, 465.

[46] C. V. Mahajan, V. Ganesan, J. Phys. Chem. B 2010, 114, 8357.

[47] D. Staufer, A. Aharony, Introduction to Percolation Theory, Taylor and Francis, London, 1992.

[48] G. Alberti, R. Narducci, M. Sganappa, J. Power Sources 2008, 178, 575 .

[49] G. Kortüm, Treatise on Electrochemistry, 2nd Ed., Elsevier, Amsterdam, New York 1965.

[50] K. Heide, Dynamische Thermische Analysenmethoden, VEB Deutscher Verlag fur Grundstoffindustrie, Leipzig, 1982.

[51] H. B. Park, C. H. Jung, Y. M. Lee, A. J. Hill, S. J. Pas, S. T. Mudie, E. V. Wagner, B. D. Freeman, D. J. Cookson, Science 2007, 318, 254. 